\title{
Reflexões sobre o Turismo Rural e o Desenvolvimento Sustentável
}

\section{Reflections on Rural Tourism and the Sustainable Development}

\author{
Andrielly Arenhart ${ }^{1}$ \\ Rosislene de Fátima Fontana ${ }^{2}$
}

\begin{abstract}
Resumo - O espaço rural, anteriormente visto por parte da sociedade como um espaço em decadência, atualmente tem sido procurado por turistas que querem sair da rotina estressante das cidades. Pelo fato de o turismo ser considerado uma atividade econômica propulsora de desenvolvimento, o turismo rural surgiu como estratégia visando o desenvolvimento rural sustentável das propriedades em dificuldade. $\mathrm{O}$ estudo teve como objetivo apresentar uma reflexão teórica sobre o turismo rural e o planejamento do mesmo relacionado com a possibilidade ou não do desenvolvimento sustentável. O trabalho caracteriza-se como um ensaio teórico com abordagem qualitativa e exploratória, realizado por meio de pesquisas bibliográficas. Com base na literatura estudada, constatou-se que a atividade pode estar relacionada com o desenvolvimento rural sustentável, desde que seja planejada e trabalhada de forma profissional pelos proprietários.
\end{abstract}

Palavras-chave: Turismo Rural; Planejamento; Gestão; Desenvolvimento Sustentável.

Abstract - The rural space, previously seen by the society as a space in decline, nowadays it has been sought by tourists who want to get out of the stressful routine of the cities. By the fact that tourism is considered an economic activity that drives development, the rural tourism has emerged as a strategy for sustainable rural development in properties that have had some problems. The study aimed to show a theoretical reflection on the rural

\footnotetext{
${ }^{1}$ Mestrado em Gestão e Desenvolvimento Regional pela Universidade Estadual do Oeste do Paraná (UNIOESTE - Campus Francisco Beltrão). Bacharelado em Hotelaria pela UNIOESTE - Campus Foz do Iguaçu. Tecnólogo em Gestão Ambiental pela Universidade Tecnológica Federal do Paraná (UTFPR Campus Medianeira). Bacharelado em Administração pelo Centro Universitário Dinâmica das Cataratas. Professora substituta nos cursos de Hotelaria e Turismo da UNIOESTE - Campus Foz do Iguaçu. E-mail: driarenhart@gmail.com

${ }^{2}$ Doutorado em Turismo e Hotelaria pela Universidade do Vale do Itajaí (UNIVALI). Mestrado em Hospitalidade pela Universidade Anhembi Morumbi (UAM). Bacharelaso em Turismo e Hotelaria pela Universidade Norte do Paraná (Unopar). Professora Adjunta na Universidade Estadual do Oeste do Paraná (UNIOESTE), atuando no Curso de Bacharelado em Hotelaria em Foz do Iguaçu e no Programa de PósGraduação em Desenvolvimento Rural Sustentável (mestrado e doutorado) em Marechal Cândido Rondon. E-mail: rosislene.fontana@unioeste.br
} 
tourism and its planning related to the possibility or not of sustainable development. The paper is characterized as a theoretical essay with qualitative and exploratory approach, carried out through bibliographical research. Based on the studied literature, it could be seen that the activity may be related to the sustainable rural development, as long as it is professionally planned and worked by the properties' owners.

Keywords: Rural Tourism; Planning; Management; Sustainable Development. 


\section{INTRODUÇÃO}

O espaço rural visto por parte da sociedade como um local em decadência, pode propiciar às pessoas que querem sair de suas rotinas no meio urbano, experiências das quais podem nunca ter tido chance, como o contato com animas, banho de cachoeiras e vivência nas atividades diárias das famílias do campo. Souza e Dolci (2019) complementam ao relatar que os cenários e atividades que envolvem agropecuária, como a produção de queijos, geleias e vinhos atraem turistas que apresentam interesse em vivenciar na prática, ou seja, que buscam experiências sensoriais e sociais em suas viagens.

Os autores Silva, Francisco e Thomaz (2010) corroboram ao afirmar que o Brasil possui propriedades rurais com potencial de riqueza cultural e paisagens naturais, nas quais podem ser desenvolvidas atividades relacionadas ao turismo rural. Assim posto, há o produtor que busca adicionar valores aos a seus produtos e formas alternativas de renda, e o turista, que busca tranquilidade e descanso na área rural para fugir da vida estressante e agitada das cidades.

Segundo Tulik (2003) e Rodrigues (2003), os termos turismo no espaço rural ou turismo em áreas rurais são considerados sinônimos de turismo rural, terminologias adotadas no desenvolvimento do trabalho. De acordo com Souza e Klein (2019a) o turismo rural teve início na década de 1980, no entanto, somente a partir da década de 1990 a temática passou a fazer parte das discussões tanto no cenário acadêmico, quanto na política brasileira.

Nesse sentido, o turismo rural surgiu como estratégia visando o desenvolvimento em áreas rurais esquecidas, sendo que seu objetivo principal era o complemento de renda para a sobrevivência dos pequenos produtores rurais. Esse fenômeno ocorreu em diversos outros países, além do Brasil (LANE, 2012). Silva, Francisco e Thomaz (2010) afirmam que a atividade nos países europeus se encontra entre as maiores referências de destinos turísticos e que em países como Espanha, França e Itália, esse segmento é considerado um dos mais importantes.

O turismo rural muitas vezes é visto pelos proprietários apenas como atividade complementar de renda, Solha (2016) aponta que estes não veem necessidade de investimentos e profissionalização. Não percebem o turismo como uma atividade 
complexa que deve ser planejada e administrada, na qual, os turistas mesmo no campo, buscam por atendimento profissional.

Assim posto, deve-se destacar a importância do planejamento do turismo rural no que concerne ao desenvolvimento rural sustentável. Não é adequado o agricultor iniciar as atividades em sua propriedade de maneira amadora, sem um levantamento inicial e realização de um projeto, sem avaliar o potencial turístico, a capacidade de carga turística do local, os impactos, viabilidade econômica e a adequação necessárias às legislações pertinentes. Sem o devido planejamento, o produtor tem o seu investimento prejudicado, assim como os turistas, pois não vivenciam a rotina do campo que realmente desejam.

Sendo assim, é possível relacionar o turismo rural com a possibilidade de desenvolvimento sustentável nas propriedades? Nesse sentido, o artigo tem como objetivo apresentar uma reflexão teórica sobre o turismo rural e o planejamento do mesmo relacionado com a possibilidade ou não do desenvolvimento rural sustentável nessas propriedades. O estudo caracteriza-se como um ensaio teórico com abordagem qualitativa e exploratória, realizado por meio de pesquisas bibliográficas.

De acordo com Cervo, Bervian e da Silva (2007) a pesquisa exploratória consiste em não requerer a elaboração de hipóteses, restringindo-se a buscar mais informações sobre determinado assunto de estudo. Lakatos e Marconi (2010) apontam que as pesquisas bibliográficas são utilizadas para a obtenção de uma ideia precisa sobre um determinado tema e contribui para o desenvolvimento do conhecimento. Para Cervo, Bervian e da Silva (2007) a pesquisa bibliográfica tem como objetivo encontrar respostas aos problemas formulados e resultam em uma integração racional dos dados levantados em um conjunto organizado, que é o ponto de chegada do processo reflexivo e que apresenta respostas aos problemas que o assunto envolve, o que resulta em um ensaio teórico.

Diante do exposto, para responder ao objetivo proposto, o estudo encontra-se estruturado em três seções: após a presente introdução, é apresentado uma revisão bibliográfica que proporciona o embasamento para a discussão do assunto e na terceira e última seção, são apresentadas as considerações finais com a síntese das explanações. 


\section{TURISMO RURAL}

Wandscheer e Teixeira (2010) afirmam que o termo rural encontra-se em um debate ainda em aberto, com carências a serem sanadas, as quais estão inseridas em uma série de fatores, como os socioeconômicos (em geral mais focalizados), englobando ainda aspectos relacionados a elementos culturais, sem esquecer a esfera ambiental.

Souza e Klein (2019c) citam que o rural é um recorte espacial e sem definição em termos de atividades econômicas. Nesse sentido, pode ou não ocorrer atividades agrícolas, as quais vem sofrendo redução, sendo que as atividades não agrícolas, como aquelas ligadas a prestação de serviços, vêm crescendo.

De acordo com Wandscheer e Teixeira (2010), a dinâmica dos espaços rurais se modificou com o surgimento de atividades desenvolvidas no meio que não estejam necessariamente voltadas exclusivamente para a agricultura. Dessa forma, ocorrem alterações estruturais nos modos de vida, no trabalho, bem como nos aspectos naturais, o que ocasiona novas concepções acerca da visão do rural, os quais já não são mais identificados com atraso e precariedade de bens e serviços, mas que representam sinônimos de qualidade de vida e bem-estar. Candiotto (2007) corrobora ao apontar que o universo rural se caracteriza por sua pluriatividade, ou seja, a disponibilidade de diversas atividades internas e externas no local, com o envolvimento de um ou mais membros da família residente na propriedade.

Assim, tem-se a atividade do turismo nas propriedades, a qual pode ser vista como uma diversificação das atividades internas e externas das explorações agrícolas, envolvendo um ou mais membros da família, ou seja, a pluriatividade. Ribeiro e Mondo (2019) caracterizam a pluriatividade como a combinação das diversas atividades ocupacionais das pessoas de uma mesma família, e apresenta como resultado as decisões tomadas pelos mesmos em âmbito individual e familiar referentes a combinação da atividade agrícola com atividades não agrícolas, baseadas no contexto social e econômico em que se encontram.

Souza, Klein e Rodrigues (2019) afirmam que as características típicas do meio rural, como sua gastronomia, as paisagens naturais e a cultura da família do campo, assim como a possibilidade de lazer e descanso para os moradores da cidade, atraem cada vez mais os moradores urbanos. Esse fato pode ser aproveitado pelas comunidades rurais, que 
devido ao desenvolvimento da economia global nas últimas décadas, encontram-se em uma situação difícil (TRUKHACHEV, 2015). Nesse contexto, Ribeiro e Mondo (2019) apontam que a oferta de lazer e acomodação para turistas, é uma forma de revalorizar as atividades do campo, de forma que próprio espaço rural é a referência ao ofertar como atrativo meios de hospedagem sem descaracterizações enquanto propriedades e edificações rurais.

O turismo rural apresenta características singulares que podem diferencia-lo do turismo convencional ou também denominado de massa. Conforme Lane (2012), a atividade surgiu, no Brasil, entre as décadas de 1970 e 1980, proveniente da busca por diferentes experiências de férias por parte dos turistas. Tulik (2003) complementa que os primeiros indícios do turismo em espaços rurais são identificados no século XX com suas atividades na Europa. A atividade surgiu na França no ano de 1948, seguido pela Espanha em 1960, Itália em 1966 e por fim, em Portugal no ano de 1978, o que posteriormente, influenciou o turismo em áreas rurais no Brasil.

Não é possível determinar com exatidão o início da atividade, mas Rodrigues (2003) relata que as primeiras iniciativas oficiais, no Brasil, se deram em 1986 no município de Lages, estado de Santa Catarina, na fazenda Pedras Brancas, a qual se propôs a receber visitantes para passar um dia no campo. Essa iniciativa passou a ser replicada em todo o território nacional, em particular na região sul e sudeste. Lane (2012) ainda relata que o surgimento da atividade foi motivado pela necessidade econômica de sobrevivência dos pequenos produtores rurais, o que não ocorreu somente no Brasil.

O conceito de turismo rural adotado pelo Ministério do Turismo (BRASIL, 2004) é de que são atividades turísticas realizadas no ambiente rural, que contribuem com a produção agropecuária, agregam valor a produtos e serviços e ainda resgatam e promovem tanto o patrimônio cultural quanto o natural da comunidade. Irshad (2010) reforça que para um local se tornar destino de turismo rural e ter sucesso, é necessário o envolvimento da comunidade, um planejamento para a realização da atividade, investimento em infraestrutura e diversas atividades para satisfazer os gostos dos visitantes.

Para Gonçalves (2016) o turismo rural delimita os acontecimentos turísticos no local, como oposição ao urbano, ou seja, limita-se à prática de qualquer atividade turística no espaço rural, incluindo diversos segmentos de turismo. A autora ainda cita que deve 
haver interesse de consumo pelos bens produzidos pelas famílias das propriedades visitadas ou do entorno e que haja interesse por parte do turista em conhecer a cultura local, a história, manifestações religiosas, folclóricas e tradicionais, assim como haver a conservação do patrimônio histórico e cultural e serviços de alimentação e hospedagem como básicos no turismo.

Um dos requisitos para ser considerado um empreendimento de turismo rural é que tenha algum tipo de comprometimento com a produção agropecuária. No entanto, a legislação brasileira ainda não contempla a diversidade de atividades não agrícolas que fazem parte da rotina destas propriedades rurais. Fato esse que se caracteriza como um desafio para esses proprietários ao atuarem em atividades, além da necessidade de atualização das leis brasileiras frente ao novo cenário apresentado no meio rural (SOLHA, 2016).

Segundo Fontana e Dencker (2006), o turismo no espaço rural deve ser visto como um complemento às atividades agrícolas do local, sem perder a essência do cotidiano da vida rural. Assim posto, Silva, Francisco e Thomaz (2010) afirmam que um fator importante no turismo rural é o tratamento dispensado pelo proprietário: seu carisma, valor humano e hospitalidade são um dos grandes destaques da atividade, sendo assim, a valorização do contato direto entre a família do proprietário e o turista é um fator essencial na relação profissional.

O turismo rural pode ter outras derivações, como o caso do turismo rural pedagógico, o qual conforme Vianna (2014), alia a atividade turística no meio rural à educação. Para a autora, se a atividade for bem planejada, torna-se positiva, uma vez que o contato com a cultura local e natural do espaço passam a ser compreendidos de forma abrangente. O segmento surge como uma possibilidade de relacionar a teoria com a prática do dia a dia, sendo que dessa forma, é possível surgir um maior interesse e oportunidade de questionamentos por parte dos alunos dos problemas enfrentados pela sociedade.

Ainda com relação às derivações que a atividade do turismo em áreas rurais pode apresentar, Trukhachev (2015) cita que é possível dividir o produto turístico rural em turismo rural 'tradicional', que engloba a acomodação da fazenda, atividades agrícolas, entre outros e em tipos 'alternativos' como a recreação rural, o lado ambiental e cultural do local. Ribeiro e Mondo (2019) ao analisarem o município de Lages, Santa Catarina, 
constataram a possibilidade dos pequenos proprietários da agricultura familiar conseguirem renda extra com a inclusão de hospedagem nas propriedades, embora os mesmos desconheçam as atividades relacionadas ao turismo e existam limitações estruturais e necessidade de investimentos.

De acordo com dados do Sebrae (2013) a atividade turística rural é eminentemente familiar e em muitos casos, os integrantes dessas famílias não são hospitaleiros ao receberem os visitantes em suas propriedades. Segundo Ribeiro e Mondo (2019) os proprietários não percebem atratividade em suas atividades rotineiras, acreditando que os turistas teriam interesse apenas no ambiente natural ou na alimentação com fartura e não no acompanhamento de suas rotinas árduas. Os mesmos reconhecem a necessidade de melhorias em suas casas e compra de enxoval, mas estariam dispostos a receber hóspedes, desde que a decisão fosse tomada por toda a família, uma vez que todos seriam beneficiados, embora ocorra uma preocupação se saberiam receber bem ou não, o turista (RIBEIRO; MONDO, 2019).

No entanto, Souza e Klein (2019b) relatam que o turismo em áreas rurais não pode ser visto como a solução para os problemas desses locais. Embora apresente impactos positivos, como a geração de ocupação para as pessoas, renda extra para os produtores e até mesmo práticas que visam a conservação e proteção das áreas naturais, pode causar perturbações como o excesso de fluxo de visitantes, turistas que deixam seus resíduos, tráfego excessivo e poluição sonora.

Ortiz e Santos (2019) afirmam que o turismo rural vem produzindo resultados variáveis no espaço rural brasileiro. Os autores concluem que a atividade é complementar às economias campesinas, que permite a reprodução do patrimônio tangível e intangível nas propriedades, mas que ainda assim, expressam um enfraquecimento do âmbito social, por meio de atividades que não apresentam um claro horizonte rumo ao futuro.

Lacay (2012) ao estudar a Rota do Pinhão, região metropolitana de Curitiba, identifica que as atividades nas propriedades rurais aconteciam de forma não planejada, além da falta de regulamentação, de infraestrutura, de envolvimento das comunidades, de capacitação profissional, entre outras carências relacionadas à organização do turismo rural. Brambatti (2019) ao analisar roteiros rurais da Região Uva e Vinho, no Rio Grande do Sul, percebeu a que decadência dos roteiros de Caxias do Sul está relacionada ao 
empreendedorismo local e às políticas públicas municipais, o que refletiu na organização e desenvolvimento dos roteiros rurais.

Nesse sentido, Solha (2016) afirma que o turismo no espaço rural se origina como uma estratégia para estimular o desenvolvimento em áreas rurais que se encontram em dificuldade, refletindo e influenciando a dinâmica do espaço rural, com presença não somente nas pequenas, mas também nas médias propriedades agrícolas. Souza e Klein (2019a) complementam que a atividade pode ser considerada com potencial para promover o desenvolvimento local, contribuindo para a dinâmica social e econômica do meio rural. E Lane (2005) afirma que a sustentabilidade do turismo rural deve ser um objetivo para ter sucesso. No entanto, há muitas dificuldades na implementação dos princípios da sustentabilidade.

\section{TURISMO RURAL E O DESENVOLVIMENTO SUSTENTÁVEL}

Ao iniciar o tópico, é necessário definir o termo desenvolvimento para uma melhor compreensão do que é o desenvolvimento rural sustentável. Souza e Klein (2019 d) relatam que desde sua aparição nos anos 50, o conceito de desenvolvimento tem sido objeto de debate, sendo atualmente um conceito multidimensional e pluridisciplinar.

Para Sen (2000) o termo desenvolvimento deve ir muito além de variáveis relacionadas a renda e acumulação de riqueza, não considerando como tal apenas o crescimento econômico. O autor aponta que o tema envolve liberdades individuais, sendo que é necessário que esteja relacionado com a melhora da vida das pessoas e de suas liberdades.

O termo desenvolvimento é bastante confundido com crescimento econômico. Souza (2007) corrobora a afirmação ao relatar que alguns pesquisadores consideram crescimento sinônimo de desenvolvimento e para outros o crescimento econômico é condição para o desenvolvimento econômico. A experiência demonstra que não se pode confundir desenvolvimento econômico com crescimento, tendo em vista que esse último nem sempre beneficia a economia como um todo e o conjunto da população, pois mesmo que a economia cresça a taxas relativamente altas ainda pode existir desigualdade social (SOUZA, 2007). 
Para Furtado (1952) o processo de desenvolvimento se baseia em uma série de mudanças nas formas em que são combinados os fatores da produção. Nesse sentido, visase conseguir combinações racionais de fatores junto ao nível da técnica utilizada, por meio da introdução de inovações técnicas, objetivando aumentar a produtividade do fator trabalho. O autor afirma que o objetivo da teoria do desenvolvimento econômico não é explicar por que a economia muda permanentemente, mas sim como o fator trabalho pode aumentar progressivamente sua produtividade.

Dessa forma, percebe-se que os conceitos de crescimento e desenvolvimento não podem ser confundidos, uma vez que crescimento não pode ser considerado desenvolvimento e sim uma condição necessária para que ocorra o desenvolvimento, embora não seja condição suficiente. $O$ desenvolvimento não leva em consideração apenas o âmbito econômico, mas também o social, cultural e o ambiental. É possível definir desenvolvimento como sendo o crescimento econômico atrelado com melhores condições de vida da população, como o acesso a saúde e educação de qualidade, acesso a moradia e oportunidades de emprego sem que ocorra grandes desigualdades e de maneira sustentável (ARENHART, 2015).

Ao se tratar de desenvolvimento rural, o conceito também se encontra em plena construção, conforme cita Conterato (2008). No entanto, ao realizar uma leitura das definições, percebe-se que as mesmas tendem a se concentrar nas melhorias das condições socioeconômicas e ambientais da população rural. Kageyama $(2004,2008)$ ainda cita que uma das principais trajetórias é a diversificação das atividades que geram renda (pluriatividade).

Ellis e Biggs (2001) afirmam que caso um novo paradigma de desenvolvimento rural surja, será aquele em que a agricultura terá lugar acompanhada de diversas outras atividades rurais e que remetem a cultura do local, e que são importantes para a construção de meios de subsistência rurais. Ainda consideram que essa diversidade de atividades pode ser a solução da política de desenvolvimento rural para reduzir a pobreza nas propriedades.

O desenvolvimento rural possui duas abordagens distintas, a primeira é o modelo exógeno em que o desenvolvimento rural desempenha um papel secundário no processo de urbanização e industrialização. A segunda abordagem é o modelo endógeno, que dá ênfase nas iniciativas locais, sendo que as instituições e organizações regionais passam a 
ter um papel fundamental no processo de desenvolvimento (MIOR, 2009. Kageyama (2009) relata a importância de se conhecer as características do local, das ações dos atores locais que visam o desenvolvimento endógeno, os quais interagem com instituições locais em busca de melhorias, para assim, contribuir com o processo de desenvolvimento rural sustentável nas propriedades.

O estudo de Oliveira e Diniz (2018) abordou os modelos de desenvolvimento baseados em turismo nas áreas rurais em Portugal. Os autores constataram a existência de produtos turísticos inovadores e indutores de desenvolvimento endógeno que é capaz de proporcionar ao turista, experiências criativas com o seu envolvimento e participação ativa nas atividades oferecidas pela comunidade.

O turismo rural depende da ação e interação dos agentes locais, ou seja, os próprios donos das propriedades e das redes de cooperação que venham a formar entre si. Nesse sentido, Silva, Francisco e Thomaz (2010) abordam a importância e necessidade de relacionamento entre associação de empreendedores e prestadores de serviços, ou seja, as redes de cooperação, pois as mesmas podem auxiliar no desenvolvimento do turismo rural quando nem sempre existe a possibilidade de implantação de todos os atrativos necessários para as atividades em uma única propriedade. Os autores ainda citam que o envolvimento de diversos empreendedores pode aumentar o tempo de permanência do visitante na região. Essa rede de colaboração também possibilita redução nas despesas. Fontana e Dencker (2006) ainda relatam que para o turismo rural ter o sucesso desejado por seus empreendedores, é necessário haver ação conjunta do Estado, proprietários rurais, instituições de ensino e crédito.

Souza e Klein (2019a) apontam que com as iniciativas governamentais que tentaram consolidar o turismo rural como vetor de desenvolvimento sustentável, a atividade adquiriu importância no cenário político, econômico e social brasileiro. No entanto, ainda há muito a ser feito para o turismo em áreas rurais se consolidar como uma atividade capaz de promover o desenvolvimento sustentável no país.

Os autores ainda afirmam que apesar de ser considerado como uma importante ferramenta para o desenvolvimento local, o turismo rural deveria ser visto como mais um elemento, entre muitos outros, que pode contribuir para diversificar economias em processo de desenvolvimento integrado e sustentável. Dessa forma, não coloca em risco ou diminuir o potencial de desenvolvimento a longo prazo. Sendo assim, consideram que 
não pode ser visto como uma panaceia para a solução de problemas de áreas rurais economicamente subdesenvolvidas e abandonadas.

De acordo com Irshad (2010) o turismo rural é utilizado como estratégia de desenvolvimento, mas é importante a parceria entre proprietários e poder público para o sucesso da atividade. Para o autor, o envolvimento e a cooperação da comunidade são características especiais do turismo rural em alguns locais, o que pode colocar em jogo o investimento de capital local, diminuir os conflitos entre os interesses dos visitantes e interesses locais e contribuir para a autenticidade das férias em áreas rurais que os turistas buscam.

Além da possibilidade de desenvolvimento do local por meio do turismo em áreas rurais, é necessário que esse ocorra de maneira sustentável. Dessa forma, a introdução do conceito de desenvolvimento sustentável, segundo Butler (1999), tem o poder de transformar as atividades, assim como o turismo em suas diversas tipologias. $\mathrm{O}$ autor considera que o conceito é atraente para quem se preocupa com as degradações no ambiente e que independentemente do motivo, o desenvolvimento sustentável é apropriado para o turismo. Ainda relata que é quase impossível apresentar desenvolvimento turístico sem que ocorra impactos sobre o local.

No entanto, o principal problema é definir com base na satisfação de todos, o que se entende por turismo sustentável. E mesmo que os elementos e processos de sustentabilidade sejam identificados, não há garantia de que irá ocorrer nas áreas de destino, sendo necessária a participação das partes interessadas no processo (BUTLER, 1999). Os autores Daniloska e Mihajlovska (2015) reforçam a necessidade de participação da comunidade local, que com base no conhecimento e amor que sentem por suas propriedades e sua cultura, podem desenvolver produtos turísticos para apoiar o desenvolvimento sustentável da região.

O turismo sustentável, segundo Bramwell et al. (2017) é visto como uma atividade que abrange aspectos sociais, culturais, econômicos, políticos e ambientais, sendo adaptável de acordo com as circunstâncias de contextos diferentes, mas relevante para todas as formas de turismo, independentemente de sua escala. Mas conforme exposto por Lane (2005), para poder afirmar que existe sustentabilidade no turismo rural, a atividade deve ser capaz de sustentar a cultura e o caráter do anfitrião, sustentar as paisagens, sustentar a economia rural, sustentar uma indústria do turismo que seja viável a longo 
prazo, desenvolver entendimento e visão aos tomadores de decisão para que não se tornem reféns apenas da atividade do turismo.

Para Vezzani (2008), o desenvolvimento do turismo rural deve ser sustentável. Segundo o autor para que ele aconteça, necessita do seguintes aspectos: apresentar melhoria nas condições de vida da população local, geração de renda complementares, crescimento econômico em áreas rurais abandonadas, o trabalho remunerado da mulher, permanência da família no campo, manutenção das atividades agropecuárias e artesanais, do patrimônio arquitetônico tradicional, além da preservação do meio ambiente e manutenção da cultura local, a participação da sociedade local no desenvolvimento da atividade, a limitação da capacidade de carga turística, entre outros.

Outro ponto importante é que ele precisa ser planejado e gerenciado. Segundo Schneider e Fialho (2000), é a sazonalidade das atividades agrícolas, da estação do ano e o fluxo de turistas, uma vez que pode sofrer variações, sendo necessário administrar ambas as atividades e os proprietários devem estar prevenidos para evitar a frustração caso o turismo rural não alcance as expectativas esperadas. Souza, Klein e Rodrigues (2019) vão além ao afirmarem que o marketing apresenta um papel crucial no sucesso dos empreendimentos. Para os autores, mesmo que a propriedade turística rural esteja bem organizada e administrada, o marketing é fundamental, uma vez que as possibilidades de divulgação foram ampliadas e transformadas, podendo citar como exemplo o caso de reservas online. Assim, é importante frisar o uso do marketing digital para promoção desses empreendimentos.

Solha (2016) afirma que para que ocorra a garantia da sustentabilidade do desenvolvimento turístico é necessário que algumas condições sejam cumpridas, tais como: a participação da sociedade local no desenvolvimento da atividade; e a limitação das capacidades de carga dos atrativos - naturais e socioculturais, e atuação sobre as infraestruturas e equipamentos, adaptando-as aos recursos turísticos a fim de preservá-los contra possíveis agressões, dentre outros.

A autora citada no parágrafo anterior complementa que a atividade apresenta contribuições importantes ao meio rural quando estudada pela ótica da sustentabilidade como: melhoria nas condições de vida da população local; contribuição para a reativação econômica de zonas deprimidas; geração de rendas complementares, incorporação do trabalho remunerado da mulher; estabilização da população local ao campo; manutenção 
das atividades agropecuárias e artesanais; manutenção e recuperação do patrimônio arquitetônico tradicional; conservação do meio ambiente e enriquecimento cultural da população local.

Ao abordar o termo desenvolvimento rural sustentável, é necessário, além de indicadores, verificar também a percepção dos residentes locais sobre a atividade turística no espaço rural, pois são afetados, tanto positivamente quanto negativamente. Souza e Klein (2019b) apontam que estudos confirmam que os efeitos são mistos, uma vez que alguns dos residentes expressam ceticismo, se não completa insatisfação, em relação às consequências do turismo em suas comunidades. Mesmo em localidades onde outras oportunidades de emprego são reduzidas, muitos moradores rejeitam oportunidades no setor turístico, devido aos baixos salários e ao caráter sazonal da ocupação. Em alguns casos, os moradores consideram a atividade turística no meio rural incoerente com as tradições culturais e tradicionais do campo (SOUZA; KLEIN, 2019B).

As autoras Fontana e Dencker (2006) alertam sobre a necessidade de acompanhamento do planejamento da atividade turística. Silva, Francisco e Thomaz (2010) apontam o planejamento como forma de estruturar as ações para oportunizar as possibilidades de sucesso e mitigar os impactos ambientais, sociais, culturais e econômicos que a atividade possa causar. E que o desenvolvimento rural deve levar em consideração o turismo nesse meio e não somente as atividades agrárias. Assim, o desenvolvimento sustentável por meio do turismo busca fazer deste uma plataforma de apresentar, divulgar e comercializar os produtos e serviços da agropecuária desenvolvidos pela agricultura familiar, agregando valor a estes, e permitindo que ocorra aumento no faturamento dessas pequenas propriedades rurais. Desta foram o turismo rural não deve ser o fim do processo, ou seja, a economia baseada nele, mas sim a ferramenta ou meio de contribuir para o desenvolvimento rural sustentável.

\section{CONSIDERAÇÕES FINAIS}

Para o desenvolvimento do trabalho foram consultados autores renomados nas áreas de turismo rural e desenvolvimento rural, além de estudos recentes sobre como se encontra a dinâmica da atividade e a possibilidade de ocorrer o desenvolvimento 
sustentável nesses locais e em seu entorno, além de apresentar algumas pesquisas com proprietários que realizam a atividade do turismo rural em suas propriedades.

O turismo rural em pequenas propriedades, deve ser utilizado como uma atividade que auxilia o proprietário com uma fonte de renda extra, incentivando o comércio dos demais produtos produzidos em sua propriedade. Não basta os proprietários pensarem que pelo fato de possuírem uma cachoeira, algum tipo de beleza natural, ou a possibilidade de ofertar passeios de animais para os visitantes, os tornam aptos para tal atividade que ainda é implantada sem os conhecimentos legais e gerenciais.

O turismo rural deve ser planejado pensando nos impactos positivos como a diminuição do êxodo rural, geração de emprego e renda a mais membros da família, consumo dos produtos das agroindústrias, valorização da cultura local e possíveis investimentos em infraestrutura locais como estradas. Há também os impactos negativos que devem ser analisados, como os impactos ambientais, excesso de visitantes além do suportado pelo local, resíduos que os turistas levam e jogam nos espaços, poluição visual e sonora, alguns proprietários podem abandonar as atividades tradicionais do campo, perdendo o caráter de homem do campo, o 'ser caipira'.

Para aumentar a probabilidade de sucesso desses empreendimentos além da formação de redes de cooperação e o associativismo, é importante o fortalecimento dessas propriedades por meio da criação de uma rota, quanto a sua divulgação, comercialização de produtos oriundos das agroindústrias da região. É interessante citar o uso da tecnologia no turismo rural, uma vez que é possível a criação de sites e aplicativos contendo informações sobre essas propriedades, comercialização dos produtos das agroindústrias. Situações que acontecem mais facilmente quando há um número maior de interessados nas propriedades do entorno.

O turismo rural pode ser uma fonte alternativa de renda, de geração empregos, de manutenção e valorização da cultura local, diminuição das desigualdades, dentre outros benefícios já citados no trabalho, os quais auxiliam para que ocorra o desenvolvimento rural sustentável. No entanto, é necessário frisar que o planejamento é essencial para que seja pensado e executado com o objetivo de desenvolver economicamente as famílias envolvidas e mitigar os impactos negativos ambientais e sociais que podem ocorrer.

Por meio das leituras, foi possível perceber que o turismo rural pode contribuir para o desenvolvimento das localidades, no entanto, ao relacionar a atividade com o 
desenvolvimento sustentável, torna-se difícil avaliar como um todo, uma vez que cada caso é único e o termo desenvolvimento sustentável pode ser interpretado de forma distinta pela comunidade.

Encontrou-se como limitações do estudo, a pouca disponibilidade de estudos relacionando o turismo rural com o desenvolvimento sustentável no Brasil. Os trabalhos utilizados versam sobre a visão dos proprietários quanto à possibilidade ou não da atividade trazer o desenvolvimento ao local, mas para esses proprietários, em sua maioria, desenvolvimento significa turistas em suas propriedades e aumento da renda. Eles não possuem uma visão ampla sobre o que de fato é desenvolvimento e as melhorias que deveriam estar acontecendo no entorno pela realização da atividade.

Sugere-se como pesquisa futura um estudo que aborde os impactos que a atividade de turismo rural traz às propriedades, com a mensuração do desenvolvimento sustentável para a comunidade com a elaboração de um indicador de desenvolvimento rural sustentável das propriedades rurais.

\section{REFERENCIAS}

ARENHART, A. Agricultura Orgânica e Desenvolvimento Rural Endógeno dos Municípios Lindeiros Paranaenses. 2015. 126p. Dissertação (Mestrado em Gestão e Desenvolvimento Regional). Programa de Pós-Graduação em Gestão e

Desenvolvimento Regional, Universidade Estadual do Oeste do Paraná, Francisco Beltrão, 2015.

BRAMBATTI, L. E. Avaliação de Roteiros de Turismo Rural: o caso da região Uva e Vinho, Rio Grande do Sul, Brasil. Turismo e Sociedade, v. 12, n. 2, p. 45-64, 2019.

BRAMWELL, B.; HIGHMAM, J.; LANE, B; MILLER, G. Twenty-five years of sustainable tourism and the Journal of Sustainable Tourism: looking back and moving forward. Journal of Sustainable Tourism, v. 25, n. 1, p. 1-9, 2017.

BRASIL. Ministério Do Desenvolvimento Agrário. Programa de Turismo Rural na Agricultura Familiar 2004/2007. Brasília, 2004.

BUTLER, R.W. Sustainable tourism: A state-of-the-art review. Tourism Geographies. v 1, n.1, p. 7-25, 1999.

CANDIOTTO, L.Z.P. Pluriatividade: aspectos históricos e conceituais. Revista Faz Ciência. v. 9., n.10. p. 191-208, 2007.

CERVO, A. L.; BERVIAN, P.A; SILVA, R. Metodologia Científica. São Paulo: Pearson Prentice Hall, 2007. 
CONTERATO, M.A. Dinâmicas regionais do desenvolvimento rural e estilos de agricultura familiar: uma análise a partir do Rio Grande do Sul. 290 p. Tese (Doutorado em Desenvolvimento Rural). Universidade Federal do Rio Grande do Sul, Porto Alegre. 2008.

COSTA, T.; GALINA, S. V. R.; SÁNCHEZ-HERNÁNDEZ, M. I. Ecossistema empreendedor no Turismo em Espaço Rural: casos de Portugal, Brasil e Espanha. Caderno Virtual de Turismo. v. 18, n. 1, p. 149-169, 2018.

DANILOSKA, N.; MIHAJLOVSKA, K. H. N. Rural tourism and sustainable rural Development. Economic Development. n.3, p. 307-320. 2015.

ELLIS, F.; BIGGS, S. Evolving Themes in Rural Development 1950s-2000s.

Development Policy Review, v.19, n.4, p.437-448, 2001.

FONTANA, R. F.; DENCKER, A. F. M. Turismo Rural: desencontros de uma realidade (2006). In: IV SEMINTUR - SEMINÁRIO DE PESQUISA EM TURISMO DO MERCOSUL. Anais... Caxias do Sul, 2006.

FURTADO, C. Formação de capital e desenvolvimento econômico. Revista Brasileira de Economia, v. 6, n. 3, p. 7-45, 1952.

GONÇALVES, A. L. C. Turismo Rural: uma abordagem conceitual. In: SEMINÁRIO DA ANPTUR, 2016. Anais... Anptur, São Paulo, 2016.

IRSHAD, H. Rural Tourism - An Overwiew. Agriculture and Rural Development. Government of Alberta, 2010.

KAGEYAMA, A. Desenvolvimento Rural: Conceito e Medida. Cadernos de Ciência \& Tecnologia, v. 21, n. 3, p. 379-408, 2004.

KAGEYAMA, A. A. Desenvolvimento rural: conceitos e aplicação ao caso brasileiro. Porto Alegre: Editora da UFRGS: Programa de Pós-Graduação em Desenvolvimento Rural, 2008.

LACAY. M. C. Desenvolvimento do turismo no espaço rural nas Rotas do Pinhão, região metropolitana de Curitiba: Convergências e conflitos das políticas públicas. 361f. Dissertação (Mestrado em Geografia). Universidade Federal do Paraná, Curitiba, 2012.

LANE, B. Sustainable Rural Tourism Strategies: A tool for development and conservation. Revista Interamericana de Ambiente y Turismo. v.1, n.1, p.12-.18, 2005.

LANE, B. Second Generation Rural Tourism: Research Priorities \& Issues. In: CONGRESSO INTERNACIONAL DE TURISMO RURAL E DESENVOLVIMENTO SUSTENTÁVEL, 2012. Anais..., Chavez, 2012. 
MARCONI, M.A.; LAKATOS, E.M. Fundamentos da Metodologia Científica. São Paulo: Atlas, 2010.

OLIVEIRA, I. D.; DINIZ. F. Turismo e Desenvolvimento Regional: uma perspectiva do turismo em espaço rural na Serra do Marão, em Portugal. Turismo e Sociedade, v. 11, n. 1, p. 113-127, 2018.

ORTIZ, H. T.; SANTOS, E. O. Enfoque Evolutivo del Turismo en Rio Grande do Sul, Brasil. Turismo e Sociedade, v. 12, n. 2, p. 1-22, 2019.

PADILHA, A. C. M; CORTE, A. D.; SOUZA, M. Diversificação de Sustento Rural a partir da Exploração do Turismo Rural: o caso da Rota das Salamarias, Marau, Rio Grande do Sul. Turismo e Sociedade, v. 12, n. 2, p. 84-109, 2019.

RIBEIRO, G. C.; MONDO, T.S. Pluriatividade Rural: a percepção de agricultores de Lages, Santa Catarina, sobre a oferta de hospedagem. Turismo e Sociedade. v. 12, n. 2 , p. 23-44, 2019.

RODRIGUES, A.B. Turismo Rural: práticas e perspectivas. 2 ed. São Paulo: Contexto, 2003

SCHNEIDER, S; FIALHO, M. A. V. Atividades não agrícolas e turismo rural no Rio Grande do Sul. In: ALMEIDA, J. A.; RIEDL, M. (Orgs.). Turismo Rural: ecologia, lazer e desenvolvimento. Bauru: Edusc, 2000.

SEBRAE. Serviço Brasileiro de Apoio às Micros e Pequenas Empresas. Retrato do turismo rural no Brasil com foco nos pequenos negócios. 2013. 56 p. Disponível em: $<$ https://bibliotecas.sebrae.com.br/chronus/ARQUIVOS_CHRONUS/bds/bds.nsf/9e845 a6d413535b25fd040f6c5ea079e/\$File/5142.pdf> Acesso em: 01 jun. 2019.

SEN, A. K. Desenvolvimento como liberdade. São Paulo: Companhia das Letras, 2000 .

SILVA, N. P.; FRANCISCO, A. C.; THOMAZ. M. S. Turismo rural como fonte de renda das propriedades rurais: um estudo de caso numa pousada rural na região dos Campos Gerais no Estado do Paraná. Caderno Virtual de Turismo. v.1, n.2, 2010.

SOLHA, K. T. A trajetória do turismo rural no estado de São Paulo: um segmento turístico em desenvolvimento.149p. Tese (Livre Docência) - Escola de Comunicação e Artes. Universidade de São Paulo, 2016.

SOUZA, M.; DOLCI, T. S. Sinergias entre turismo e atividades agrícolas: o exemplo do enoturismo. In: SOUZA, M.; DOLCI, T. S. (Orgs). Turismo rural: fundamentos e reflexões. Porto Alegre: Editora da UFRGS, 2019. p. 99-117. 
SOUZA, M.; KLEIN, A. L.(a) Normativas, regulamentações e políticas públicas para o turismo rural. In: SOUZA, M.; DOLCI, T. S. (Orgs). Turismo rural: fundamentos e reflexões. Porto Alegre: Editora da UFRGS, 2019. p. 41-60.

SOUZA, M.; KLEIN, A. L.(b); Processo turístico no espaço rural: impactos e planejamento. In: SOUZA, M.; DOLCI, T. S. (Orgs). Turismo rural: fundamentos e reflexões. Porto Alegre: Editora da UFRGS, 2019. p. 61-82.

SOUZA, M.; KLEIN, A. L.(c); Rural, Ruralidade, pluriatividade e multifuncionalidade do desenvolvimento rural. In: SOUZA, M.; DOLCI, T. S. (Orgs). Turismo rural: fundamentos e reflexões. Porto Alegre: Editora da UFRGS, 2019. p. 9-22.

SOUZA, M.; KLEIN, A. L.(d); Turismo e desenvolvimento rural. In: SOUZA, M.; DOLCI, T. S. (Orgs). Turismo rural: fundamentos e reflexões. Porto Alegre: Editora da UFRGS, 2019. p. 83-98.

SOUZA, M.; KLEIN, A. L.; RODRIGUES, R. G. Turismo Rural: conceitos, tipologias e funções. In: SOUZA, M.; DOLCI, T. S. (Orgs). Turismo rural: fundamentos e reflexões. Porto Alegre: Editora da UFRGS, 2019. p. 23-40.

SOUZA, N. J. Desenvolvimento Econômico. São Paulo: Atlas, 2007.

TRUKHACHEV, A. Methodology for Evaluating the Rural Tourism Potentials: A Tool to Ensure Sustainable Development of Rural Settlements. Sustainability. v. 7, p. 3052-3070, 2015.

TULIK, O. Turismo rural. São Paulo: Aleph. Coleção ABC. 2003.

VEZZANI, M. A. Turismo rural e responsabilidade ambiental e ecológica no espaço rural brasileiro. Caderno Virtual de Turismo. v. 8, n 1. p. 27-39. 2008.

VIANNA, T. E. O turismo rural pedagógico focado na educação ambiental como ferramenta complementadora do ensino fundamental. Turismo e Sociedade, v. 7, n. 4, p. 755-774, 2014.

WANDSCHEER, E. A. R.; TEIXEIRA, A. R. Novas ruralidades: demandas e potencialidades da sociedade contemporânea. In: SANTOS, E. O.; SOUZA, M. Teoria e prática do turismo no espaço rural. São Paulo: Manole, 2010. p. 47-58.

Recebido em: 11-09-2019.

Aprovado em: 30-05-2020. 